\title{
Optimization of Income Tax at North Karawang North KPP
}

\author{
Liya Megawati \\ Novian Ekawaty \\ Universitas Singaperbangsa Karawang \\ J1. H. Ronggowaluyo Teluk Jambe Timur Karawang Barat \\ liyamegawati67@gmail.com \\ novianekawaty@yahoo.com
}

This study aims to determine how the optimization of income tax revenue carried out by KPP Pratama Karawang Utara, Karawang Regency. To answer this problem, researchers used a descriptive qualitative approach. The object of this research is North Karawang Pratama KPP Regency. The data of this study were obtained from secondary data and interviews conducted at North Karawang North KPP employees. The results of this study indicate that the implementation of the optimization of income tax receipts at North Karawang North Tax Office is not optimal, because there are still obstacles in its implementation.

\section{Keyword: income tax, North Karawang North Tax Office PENDAHULUAN}

Keuangan negara sebagai bagian terpenting dalam pelaksanaan pembangunan nasional yang pengelolaannya diimplementasikan dalam Anggaran Pendapatan dan Belanja Negara (APBN) maupun Anggran Pendapatan dan Belanja Daerah (APBD) merupakan pilar utama pembiayaan penyelenggaraan negara. Ruang lingkup keuangan negara salah satunya meliputi penerimaan negara. Sumber utama penerimaan negara yang digunakan untuk membiayai pengeluaran rutin maupun pembangunan agar tercapai kemakmuran dan kesejahteraan masyarakat yaitu bersumber dari sektor pajak.

Pajak penghasilan merupakan kewajiban yang harus dilunasi oleh wajib pajak orang pribadi maupun badan yang telah memperoleh penghasilan dalam bentuk apapun sehingga dapat digunakan untuk memenuhi segala kebutuhan Negara. Dalam pemungutan pajak, Indonesia menggunakan sistem Self Assesment yaitu wajib pajak diberikan kebebasan penuh untuk menentukan sendiri besarnya pajak yang harus dibayar, sedangkan pihak fiskus bertugas sebagai pengawas sesuai dengan Undang - Undang yang didalamnya telah diatur mekanisme kontrol dan sanksi - sanksi bagi wajib pajak yang tidak memenuhi kewajiban perpajakannya secara benar dan tepat waktu. Kenyataannya dalam penerimaan pajak saat ini belum sesuai dengan harapan pemerintah, disebabkan karena wajib pajak dalam membayar kewajiban 
pajaknya tidak tepat waktu dan bahkan tidak sedikit pengusaha yang tidak melaporkan usahanya sehingga penerimaan pajak tidak dapat maksimal.

Permasalahan yang terjadi di Kantor Pelayanan Pajak (KPP) Karawang Utara yaitu tidak tercapainya target penerimaan pajak penghasilan. Realisasi penerimaan pajak penghasilan pada Kantor Pelayanan Pajak (KPP) Karawang Utara pada tahun 2017 dan 2018 realiasasinya sudah melampaui target, tetapi pada tahun 2014, 2015, dan 2016 penerimaan pajak penghasilan reaslisasinya tidak mencapai target. Mengingat Pajak Penghasilan merupakan andalan dari penerimaan pajak yang paling besar menyumbang ke kas negara, tentunya hal ini akan berdampak pada penerimaan negara.

Berdasarkan latar belakang masalah tersebut, sehubungan dengan pentingnya optimalisasi penerimaan pajak penghasilan pada KPP Karawang Utara, maka penulis tertarik untuk mengkaji lebih lanjut dalam sebuah penelitian yang berjudul "Optimalisasi Penerimaan Pajak Penghasilan (Studi Kasus pada Kantor Pelayanan Pajak Karawang Utara)"

\section{TINJAUAN PUSTAKA}

\section{Tinjauan Pajak}

Pajak merupakan salah satu penerimaan negara yang memberikan kontribusi paling besar terhadap kas negara. Pajak adalah iuran wajib yang dipungut oleh pemerintah dari masyarakat (wajib pajak) yang bersifat memaksa untuk menutupi pengeluaran rutin negara dan biaya pembangunan tanpa balas jasa yang dapat ditunjuk secara langsung.

\section{Tinjauan Pajak Penghasilan}

Pajak Penghasilan merupakan andalan dari penerimaan pajak yang paling besar menyumbang ke kas Negara. Kontribusi pajak penghasilan kepada penerimaan Negara diharapkan semakin meningkat sebagai cerminan kepedulian pihak yang dianggap memiliki penghasilan berlebihan oleh undang - undang kepada pembiayaan Negara.

\section{Tarif Pajak Penghasilan}

Menurut Supramono (2015:64), tarif pajak penghasilan yang berlaku menurut pasal 36 UU Pajak Penghasilan Tahun 2008 dibagi menjadi dua yaitu untuk wajib pajak orang pribadi dan wajib pajak badan. Tarif untuk wajib pajak orang pribadi menggunakan tarif pajak progresif dan dikenakan secara berlapis sesuai dengan penghasilan wajib pajak orang pribadi yang bersangkutan, sedangkan bagi wajib pajak badan menggunakan tarif pajak proporsional yaitu sebesar $28 \%$. 
Bagi wajib pajak badan dalam negeri yang berbentuk perseroan terbuka yang paling sedikit $40 \%$ (empat puluh persen) dari jumlah keseluruhan saham yang disetor diperdagangkan dibursa efek di Indonesia dan memenuhi persyaratan tertentu lainnya dapat memperoleh tarif sebesar 5\% (lima persen) lebih rendah.

Tarif bagi wajib pajak badan ini akan diturunkan menjadi 25\% mulai tahun 2010. Bagi wajib pajak badan dalam negeri dengan peredaran bruto sampai dengan Rp. 50.000.000.000,00 (lima puluh milyar rupiah) mendapat fasilitas berupa pengurangan tarif sebesar $50 \%$ (lima puluh persen) dari tarif sebagaimana dimaksud dalam Pasal 17 yaitu $25 \%$ yang dikenakan atas penghasilan kena pajak (PKP) dari bagian peredaran bruto sampai dengan Rp. 4.800.000.000,00 (empat miliar delapan ratus juta rupiah). Oleh sebab itu, dengan adanya fasilitas ini wajib pajak yang memiliki peredaran bruto sampai dengan Rp. 50.000.000.000,00 (lima puluh miliar rupiah) atas peredaran bruto yang sebesar Rp. 4.800.000.000,00 (empat miliar delapan ratus juta rupiah) hanya dikenakan tarif pajak 12,5\%.

Berbeda dengan wajib pajak badan yang menggunakan tarif tunggal, wajib pajak orang pribadi menggunakan tarif pajak yang berlapis. Lapisan tarif pajak untuk wajib pajak orang pribadi ditentukan sebagai berikut :

Tabel 2.2

Tarif Pajak bagi Wajib Pajak Orang Pribadi

\begin{tabular}{|c|c|}
\hline LAPISAN PENGHASILAN KENA & TARIF \\
PAJAK & PAJAK \\
\hline Sampai dengan Rp. 50.000.000,00 & $5 \%$ \\
\hline Di atas Rp. 50.000.000,00 - Rp. 250.000.000,00 & $15 \%$ \\
\hline Di atas Rp. 250.000.000,00 - Rp. 500.000.000,00 & $25 \%$ \\
\hline Di atas Rp. 500.000.000,00 & $30 \%$ \\
\hline
\end{tabular}

(Sumber : KPP Pratama Karawang Utara, diolah peneliti)

Berdasarkan tabel di atas, dapat dilihat bahwa pada tahun 2014 penerimaan pajak penghasilan di KPP Pratama Karawang Utara Kabupaten Karawang realisasinya tidak mencapai $100 \%$, realisasinya hanya mencapai 95,63\%. Sedangkan pada tahun 2015 realisasinya lebih menurun hanya mencapai $74,85 \%$ dan pada tahun 2016 realisasinya mencapai $81,56 \%$. Setelah dihitung berdasarkan rata - rata, bahwa rata - rata target penerimaan pajak penghasilan KPP Pratama Karawang Utara Kabupaten Karawang dari tahun 2014 - 2018 
yaitu sebesar Rp. 2.570.103.935.040, sedangkan rata - rata realisasinya yaitu sebesar Rp. 2.344.357.407.958 dan persentasenya hanya mencapai 90,94\% tidak mencapai 100\%. Berdasakan hal tersebut, dapat dilihat bahwa dihitung berdasarkan rata - rata target penerimaan pajak penghasilan KPP Pratama Karawang Utara Kabupaten Karawang tidak mencapai rata rata realisasinya.

Mengingat pajak penghasilan merupakan andalan dari penerimaan pajak yang paling besar menyumbang ke kas negara, tentunya aparat pajak (fiscus) melakukan upaya untuk mengoptimalisasikan penerimaan pajak penghasilan. Kontribusi pajak penghasilan kepada penerimaan Negara diharapkan semakin meningkat sebagai cerminan kepedulian pihak yang dianggap memiliki penghasilan berlebihan oleh undang - undang kepada pembiayaan Negara.

Berikut ini hasil wawancara dengan tiga (3) informan mengenai pelaksanaan optimalisasi penerimaan pajak penghasilan di KPP Pratama Karawang Utara Kabupaten Karawang. Berdasarkan hasil wawancara dengan Informan 1 (AR, akun representatif KPP Pratama Karawang Utara) pada tanggal 14 September 2019 mengenai kejelasan, kepastian, dan kesederhanaan peraturan perundang - undangan perpajakan, beliau menjelaskan bahwa berbicara mengenai peraturan perpajakan, pembuatan Undang - Undang Perpajakan itu berada di Pemerintah Pusat dan Direktorat Jendral Pajak yang memiliki Sub Direktorat Peraturan yang mengatur masalah Pajak Pertambahan Nilai (PPN), yang mengatur masalah Pajak Penghasilan, dan sebagainya. Pada saat peraturan tersebut diterbitkan, KPP Pratama Karawang Utara hanya bisa mengikuti aturan tersebut, setelah itu KPP Pratama Karawang Utara mengkaji peraturannya, selanjutnya petugas pajak dilakukan bimtek, setelah petugas pajak diberikan bimbingan, KPP Pratama Karawang Utara melakukan sosialisasi ke masyarakat khususnya wajib pajak penghasilan terkait peraturan tersebut. Undang - Undang itu merupakan dasar hukum yang paling tinggi. Jadi, hukum perpajakan di Indonesa itu selalu mengacu kepada Undang - Undang yang dijadikan dasar hukum. Yang menjadi dasar hukum pajak penghasilan yaitu Undang - Undang Republik Indonesia No. 7 Tahun 1983 tentang Pajak Penghasilan sebagaimana telah beberapa kali diubah terakhir dengan Undang - Undang Republik Indonesia No. 36 Tahun 2008.

Selanjutnya, berdasarkan hasil wawancara dengan Informan 2 (SP, Seksi Pelayanan Perpajakan KPP Pratama Karawang Utara) pada tanggal 8 September 2019, beliau menjelaskan bahwa terkait pemungutan pajak penghasilan di Indonesia menganut Self Assessment, jadi pelayanan perpajakan yang diberikan oleh KPP Pratama Soreang hanya sebatas administrasinya saja. Sebagai wujud nyata kepedulian petugas pajak pada pentingnya kualitas 
pelayanan terhadap wajib pajak penghasilan, petugas pajak memberikan pelayanan kepada wajib pajak melalui :

1) Pengarahan kepada wajib pajak penghasilan apabila ada wajib pajak yang tidak terbiasa menggunakan internet untuk membuat kode billing, pengarahan tersebut bisa melalui telepon ataupun datang langsung ke KPP Pratama Soreang.

2) Penyuluhan tentang e-filling, agar wajib pajak penghasilan tidak lupa untuk selalu menyampaikan SPT Masa atau SPT Tahunan.

3) Ketika wajib pajak datang ke KPP Pratama Soreang untuk membuat NPWP, petugas pajak selain memberikan pelayanan untuk membuat NPWP, petugas pajak juga memberikan penjelasan kepada wajib pajak baru akan kewajiban perpajakannya.

Berdasarkan hasil wawancara dengan Informan 3 (SE, Seksi Ekstensifikasi Perpajakan KPP Pratama Soreang) pada tanggal 8 September 2019, beliau menjelaskan bahwa dalam memberikan pelayanan perpajakan kepada wajib pajak penghasilan, KPP Pratama Soreang harus memiliki sarana dan prasarana yang memadai, yaitu :

1) Komputer yang memadai untuk memberikan pengarahan kepada wajib pajak penghasilan yang datang langsung ke KPP Pratama Soreang untuk registrasi $e$-filling apabila wajib pajak tersebut tidak terbiasa menggunakan internet.

2) Formulir SPT Tahunan selalu tersedia di KPP Pratama Soreang.

3) Percetakan ID Billing yaitu khusus wajib pajak penghasilan yang datang ke KPP Pratama Soreang untuk membuat Kode Billing.

Berdasarkan hasil observasi dan wawancara, peneliti dapat menganalisis bahwa pelayanan perpajakan khususnya pajak penghasilan yang diberikan oleh petugas pajak KPP Pratama Soreang kepada wajib pajak penghasilan merupakan hal terpenting, karena semakin baik pelayanan yang diberikan maka wajib pajak tidak akan merasa enggan atau lebih merasa senang dalam melakukan pembayaran pajak penghasilan dan penerimaan pajak penghasilan di KPP

Pratama Soreang akan menjadi optimal. KPP Pratama Soreang harus bisa membantu segala kesulitan yang dihadapi oleh wajib pajak penghasilan di dalam pembayaran pajaknya, mulai dari melaporkan SPT sampai pembayaran pajak.

Berdasarkan hasil wawancara dengan Informan 3 (SE, Seksi Ekstensifikasi Perpajakan KPP Pratama Karawang Utara) pada tanggal 28 Agustus 2019, beliau menjelaskan bahwa Undang - Undang Pajak Penghasilan merupakan urusan internal, tetapi apabila membahas mengenai peraturan perundang - undangan perpajakan wewenangnya bukan di KPP tetapi sudah di pusat, bisa di Direktorat Jendral Pajak ataupun Kementerian Keuangan. KPP memiliki 
tugas untuk memberikan penyuluhan yaitu kewajiban memberikan informasi tentang kejelasan, kepastian, dan kesederhanaan Undang - Undang Perpajakan. Penyuluhan disini kita memberikan informasi tentang peraturan - peraturan perpajakan khususnya pajak penghasilan agar kepastian hukumnya ada, kejelasannya juga ada, kesederhanaan formulir dalam mengisi Surat Pemberitahuan (SPT), KPP Pratama Karawang Utara harus bisa memberikan informasi itu. Pajak penghasilan memiliki banyak sekali wajib pajaknya baik orang pribadi atau badan yang perlu diberi pemahaman mengenai aturan undang - undang pajak penghasilan agar wajib pajak memahami dan mengetahui kewajibannya sebagai wajib pajak.

Berdasarkan hasil observasi dan wawacara diatas dapat disimpulkan mengenai kejelasan, kepastian, dan kesederhanaan peraturan perundang - undangan perpajakan, peneliti dapat menganalisis bahwa peraturan perundang - undangan perpajakan khususnya pajak penghasilan sudah ada kejelasan, kepastian, dan kesederhanannya yang dapat memberikan presepsi masyarakat atau wajib pajak untuk memenuhi kewajiban perpajakannya sesuai dengan ketentuan perpajakan yang belaku. Kemudian dengan dilakukannya sosialisasi atau pendekatan persuasif, pelayanan kepada masyarakat atau wajib pajakpun akan lebih meningkat, karena kesadaran dan pemahaman wajib pajak erat kaitannya dengan seberapa besar bentuk sosialisasi dan pelayanan yang diberikan oleh petugas pajak.

Pelayanan perpajakan khususnya pajak penghasilan yang diberikan oleh petugas pajak KPP Pratama Karawang Utara kepada wajib pajak penghasilan merupakan hal terpenting, karena semakin baik pelayanan yang diberikan maka wajib pajak tidak akan merasa enggan atau lebih merasa senang dalam melakukan pembayaran pajak penghasilan dan penerimaan pajak penghasilan di KPP Pratama Soreang akan menjadi optimal. KPP Pratama Soreang harus bisa membantu segala kesulitan yang dihadapi oleh wajib pajak penghasilan di dalam pembayaran pajaknya, mulai dari melaporkan SPT sampai pembayaran pajak. Dengan demikian hal ini akan memperlancar penerimaan negara dari sektor pajak.

\section{KESIMPULAN}

Berdasarkan hasil penelitian dan pembahasan yang telah dilakukan, maka diperoleh kesimpulan bahwa pelaksanaan optimalisasi penerimaan pajak penghasilan di KPP Pratama Karawang Utara dengan mangacu kepada enam (6) faktor. Pertama, kejelasan, kepastian, dan kesederhanaan Undang - Undang No. 36 Tahun 2008 tentang Pajak Penghasilan. Kedua, kebijakan pemerintah yang dijalankan KPP Pratama Karawang Utara dalam mengimplementasikan Undang - Undang Perpajakan salah satunya yaitu ekstensifikasi dan intensifikasi perpajakan. Ketiga, sistem administrasi perpajakan yang digunakan oleh KPP 
Pratama Karawang Utara yaitu DJP Online dan SIDJP. Keempat, pelayanan perpajakan khususnya pajak penghasilan yang diberikan KPP Pratama Karawang Utara kepada wajib pajak

yaitu memberikan pengarahan dan penyuluhan mengenai sistem administrasi perpajakan DJP Online. Kelima, dalam meningkatkan kesadaran dan pemahaman warga negara KPP Pratama Karawang Utara menggunakan pendekatan persuasif atau sosialisasi kepada wajib pajak mengenai pajak penghasilan. Keenam, kualitas petugas pajak KPP Pratama Karawang Utara tercermin pada lima (5) nilai - nilai Kementerian Keuangan. Dalam penelitian ini, pelaksanaan optimalisasi penerimaan pajak penghasilan di KPP Pratama Karawang Utara belum optimal, dikarenakan masih terdapat hambatan - hambatan dalam pelaksanaannya.

\section{DAFTAR PUSTAKA}

Akadun. 2009. Administrasi Perusahaan Negara. Bandung: Alfabeta.

Anggara, Sahya. 2012. Ilmu Administrasi Negara. Bandung: Pustaka Setia.

Bungin, Burhan.2006. Metode Penelitian Kualitatif. Jakarta : Raja Grafindo Persada.

Gunadi, Djoned M. 2005. Administrasi Pajak. Jakarta : BPPK DEPKEU RI.

Hasibuan, Melayu. 2003. Manajemen Sumber Daya Manusia. Jakarta : Bumi Aksara.

Mansury, R. 2002. Pajak Penghasilan Lanjutan Pasca Reformasi 2000. Jakarta : YP4.

Moleong, J. Lexy. 2009. Metodologi Penelitian Kualitatif. Bandung: Remaja Rosdakarya.

Nasution, S. 1995. Metode Research. Jakarta: Bumi Aksara.

Pasolong, Harbani. 2013. Teori Administrasi Publik. Bandung : Alfabeta.

Prasetyono, Dwi Sunar. 2012. Buku Pintar Pajak. Yogyakarta : Laksana.

Rahayu, Siti Kurnia. 2010. Perpajakan Indonesia. Yogyakarta : Graha Ilmu.

Rahman, Abdul. 2010. Panduan Pelaksanaan Administrasi Perpajakan untuk

Karyawan, Pelaku Bisnis, dan Perusahaan. Bandung : Nuansa Cendekia.

Resmi, Siti. 2009. Perpajaka Edisi Kelima. Jakarta : Salemba Empat.

Ridwan, Juniarso dan Ahmad Sodik. 2012. Hukum Administrasi Negara dan Kebijakan Pelayanan Publik. Bandung : Nuansa.

Rusjdi, Muhammad. 2007. PPh Pajak Penghasilan. Yogyakarta : Index. 
Sakti. Fajar Tri. 2014. Sisi Gelap Perencanaan. Bandung : FISIP UNPAS Press. Sari, Diana. 2013. Konsep Dasar Perpajakan. Bandung : Refika Aditama. Simanjuntak, Timbul H dan Imam Mukhlis.2012. Dimensi Ekonomi Perpajakan Sugiyono. 2006. Metodologi Penelitian Administratif. Bandung : Alfabeta.

. 2011. Metode Penelitian Kuantitatif, Kualitatif dan R\&D. Bandung: Alfabeta. . 2016. Metode Penelitian Kuantitatif, Kualitatif dan R\&D. Bandung: Alfabeta. Supramono, Theresia. 2015. Perpajakan Indonesia Mekanisme \& Perhitungan. Yogyakarta : Andi.

Zain, Muhammad. 2005. Manajemen Perpajakan. Jakarta : Salemba. 